\title{
青藏高原念青唐古拉峰冰川区夏季风期间 大气气溶胶元素特征
}

\author{
李潮流 ${ }^{\circledR \oslash}$ 康世昌 ${ }^{\circledR{ }^{*}}$ 丛志远 ${ }^{\circledR \otimes}$
}

(1) 中国科学院青藏高原研究所纳木错圈层相互作用综合观测研究站, 北京 100085; (2) 中国科学院研究生院, 北京 100049;

(3) 中国科学院冰冻圈科学国家重点实验室, 兰州 730000.*联系人, E-mail: shichang.kang@itpcas.ac.cn)

\begin{abstract}
摘要 为了研究夏季风期间青藏高原冰川区的大气气溶胶元素特征及其来源, 于 2006 年 6 10月, 在青 藏高原南部念青唐古拉峰扎当冰川垭口 $\left(30^{\circ} 28^{\prime} \mathrm{N}, 90^{\circ} 39^{\prime} \mathrm{E}, 5800 \mathrm{~m}\right.$ a.s.1.)采集了 7 个大气总悬浮颗粒物样 品, 利用 ICP-MS 测定了样品中 27 种元素的含量. 结果表明, 垭口冰川区大气气溶胶的元素浓度, 特别 是典型地壳元素的浓度不仅低于同时期该地区较低海拔的气溶胶元素值, 而且远低于青藏高原其他较 低海拔地区(如五道梁、瓦里关站等)的值. 因而冰川区的气溶胶代表了青藏高原对流层中上部大气的本 底状况. 元素富集因子的研究表明, 与人类活动密切相关的元素(如 $\mathrm{B}, \mathrm{Zn}, \mathrm{As}, \mathrm{Cd}, \mathrm{Pb}, \mathrm{Bi}$ )有较高的富 集, 由于夏季青藏高原南部大气环境主要受西南夏季风影响, 气团轨迹也显示该时期的气团来自南亚 大陆，因而推断南亚的污染物在夏季风期间影响了青藏高原冰川区的大气环境.
\end{abstract}

\section{关键词 青藏高原 纳木错 气溶胶 元素 大气污染}

大气气溶胶在全球气候变化过程中具有重要作 用, 它不仅可以影响地表辐射平衡, 还能通过向海洋 输送营养物质促进海洋浮游生物的生长, 调节海气 间的 $\mathrm{CO}_{2}$ 交换 ${ }^{[1 \sim 2]}$, 高层大气气溶胶的背景值也是评 价全球大气模型的重要数据. 不仅如此, 大气气溶胶 还可以携带其他大气污染物进行长距离传输 [3]. 研 究表明, 全球偏远地区和高海拔地区大气中的重金 属含量可以揭示全球工业污染状况并评价环境质量 [4]. 在南北极冰雪和大气气溶胶中已经检测到人类活

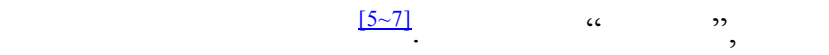
中低纬度的青藏高原尽管自身的人类活动较少, 但 由于毗邻南亚和东亚人类聚居区, 因而具有监测全 球, 尤其是中低纬度大气环境变化的独特优势. 从青 藏高原冰雪中已经检测到来自南亚和中东的污染物 [4,8 10]. 近年来在青藏高原已经开展了一些大气气溶 胶的研究 ${ }^{[11 ~ 16]}$, 其中对纳木错地区夏季风期间大气 气溶胶的监测发现了从南亚传入的污染物 ${ }^{[15]}$.

因此目前对远距离传输至青藏高原的大气污染 物的研究一般有两种手段: 在冰川区采集冰雪和在 海拔相对较低的地点采集大气气溶胶. 但前者只是 间接的研究而后者容易受到局地人类活动的影响 [13 16]. 由于处在对流层中上部的冰川区不但能反映
大尺度的大气状况，而且远离局地潜在污染源 ${ }^{[17],}$ 因此有必要在冰川区直接采集大气气溶胶分析其化 学成分. 基于这一思路我们于 2006 年夏季风期间, 采集并研究了位于青藏高原南部的念青唐古拉峰扎 当冰川区的大气气溶胶元素组成. 该点位于纳木错 站的采样地点西南约 $50 \mathrm{~km}$.

\section{1 样品采集和测试}

采样点 $\left(30^{\circ} 28^{\prime} \mathrm{N}, 90^{\circ} 39^{\prime} \mathrm{E}, 5800 \mathrm{~m}\right.$ a.s.1)位于念青 唐古拉山主峰东北侧的扎当冰川垭口(图 1). 气溶胶 采样器安装有一台真空洜, 用太阳能电池板和蓄电 池联合供电, 空气流量由自动流量计(Taihe Automation Control and Instrument Corp.)记录, 瞬时流量约 为 $0.40 \mathrm{~m}^{3} / \mathrm{h}$. 空气流量按冰川区的气象参数转化为 标准体积. 2006 年 6 月 25 日 10月 15 日共采集到 7 个 Teflon 滤膜样品(时间间隔一到两周不等). 采集到 的样品用电感耦合等离子体质谱仪 (ICP-MS, X-7 Thermo Elemental)测定了 27 种元素 $(\mathrm{Li}, \mathrm{Be}, \mathrm{B}, \mathrm{Na}$, $\mathrm{Mg}, \mathrm{Al}, \mathrm{K}, \mathrm{Ca}, \mathrm{Sc}, \mathrm{Ti}, \mathrm{V}, \mathrm{Fe}, \mathrm{Mn}, \mathrm{Zn}, \mathrm{Ga}, \mathrm{As}, \mathrm{Rb}, \mathrm{Sr}, \mathrm{Y}$, $\mathrm{Cd}, \mathrm{Cs}, \mathrm{Ba}, \mathrm{Tl}, \mathrm{Pb}, \mathrm{Bi}, \mathrm{Th}, \mathrm{U})$ 的质量浓度 $\left(\mathrm{ng} / \mathrm{m}^{3}\right)$. 在 室内外的所有操作过程中都采取严格措施防止可能 的污染, 空白样也进行和样品同样的操作. 所有测定 


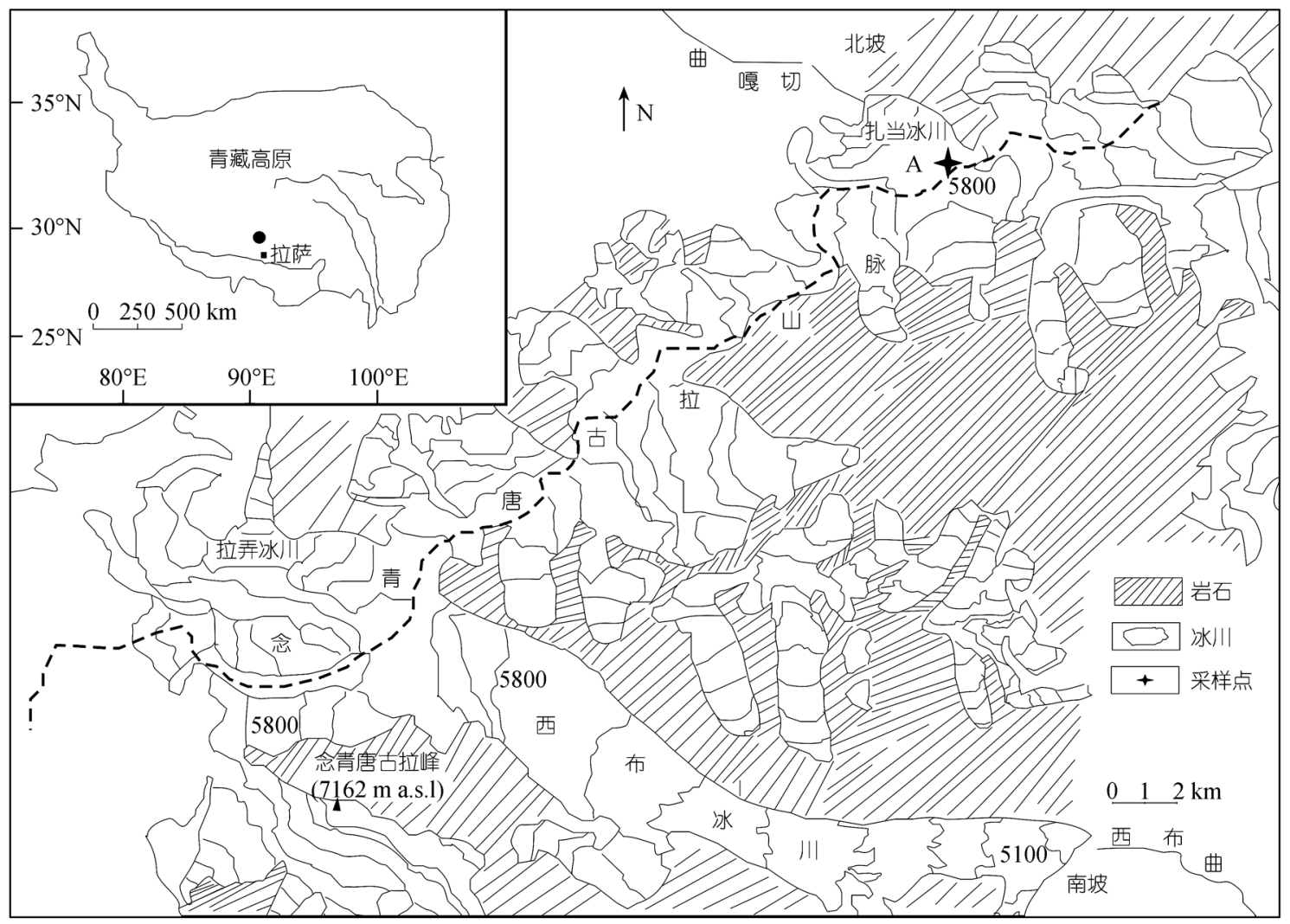

图 1 采样点位置图

元素的值均远高出仪器检测限(空白样的 3 倍标准偏 差), 测定结果经国家黄土标准参考物质(GBW07408) 验证精密度和准确度良好, 参考物质中除 $\mathrm{Cd}$ 的相对 标准偏差(RSD)为 13\%外其余元素均小于 5\%, 所有 元素的回收率在 $81 \%(\mathrm{~V})$ 至 $115 \%(\mathrm{~Pb})$ 之间.

此外，在垭口还架设有一台自动气象站 (Campbell 公司), 观测探头每 $60 \mathrm{~s}$ 测定一次风速、风 向、温度、相对湿度、气压等气象要素, 数据采集器 每 $30 \mathrm{~min}$ 对上述各要素计算平均值并记录(表 1). 采 样期间的平均气温较低 $\left(-0.89^{\circ} \mathrm{C}\right)$, 但气温变幅较大 $\left(23.4^{\circ} \mathrm{C}\right)$. 相对湿度变化范围为 $15.51 \% \sim 100 \%$. 垭口 风速较大, 最大风速达 $17.1 \mathrm{~m} / \mathrm{s}$, 盛行风向为偏南风 (图 2), 表明该时段主要受西南夏季风的影响.

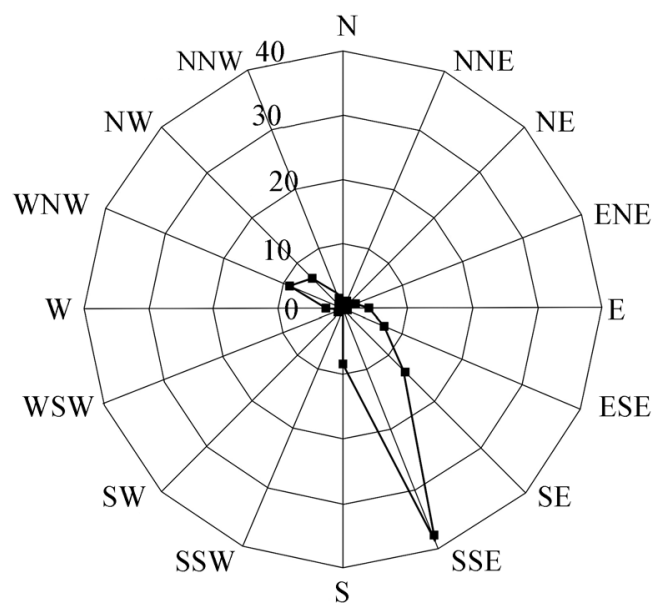

图 2 采样期间的风向玫瑰图

表 1 采样期间的基本气象参数 ${ }^{\text {a) }}$

\begin{tabular}{llccc}
\hline 指标 & 精度 & 平均值 & 标准偏差 & 变化范围 \\
\hline 气压 $/ \mathrm{hPa}$ & \pm 0.25 & 504.68 & 1.32 & $499.50 \sim 508.30$ \\
气温 $/{ }^{\circ} \mathrm{C}$ & \pm 0.2 & -0.89 & 2.31 & $-13.14 \sim 10.28$ \\
湿度 $(\%)$ & $\pm(2 \% \sim 3 \%)$ & 79.74 & 15.25 & $15.51 \sim 100$ \\
风速 $/ \mathrm{m} \cdot \mathrm{s}^{-1}$ & \pm 0.3 & 5.00 & 2.83 & $0.00 \sim 17.10$ \\
\hline
\end{tabular}

a) 所列各指标的平均值和标准偏差依据日平均值得到, 变化范围所列数值取自采样期间各指标的极小值和极大值 


\section{2 结果和讨论}

\section{1 冰川区气溶胶的元素组成}

冰川区气溶胶元素的平均含量见表 2 , 同时也列 出了该地区 2005 年季风期间的数据和青藏高原其他 地区及南极洲和北京的数据. 可以看出 $\mathrm{Na}, \mathrm{Mg}, \mathrm{Al}, \mathrm{K}$, $\mathrm{Ca}, \mathrm{Fe}$ 是垭口冰川区气溶胶中的主要元素, 这 6 种元 素的质量浓度约占测定元素总和的 $95.2 \%$. 将扎当冰 川区气溶胶元素的平均含量与纳木错站 2005 年季风 期间的采样结果进行对比可见: 冰川区气溶胶中地 壳元素如 $\mathrm{Al}, \mathrm{K}, \mathrm{Ca}, \mathrm{Fe}, \mathrm{Mn}$ 的含量远低于纳木错站相 应元素的含量, 其中 $\mathrm{Ca}$ 和 $\mathrm{Mn}$ 的含量仅约为纳木错站 的 $1 / 5$. 已有研究表明, 青藏高原低海拔地区的大气 气溶胶主要来自局地粉尘 ${ }^{[14]}$, 而高海拔冰川区比低 海拔的大气洁净得多, 几乎没有局地气溶胶的输入 [21]. 本文的研究结果与上述结论一致, 进一步说明高
海拔地区大气气溶胶反映的是大尺度而非局地的大 气状况. 与地壳元素明显不同的是冰川区气溶胶中 重金属 $\mathrm{Zn}$ 和As的含量与纳木错站相差不大，可能原 因是这两种元素主要由夏季风从南亚地区传输而来, 因此它们不受局地粉尘的影响而在不同海拔的大气 中具有比较一致的含量. 青藏高原北部瓦里关站和 五道梁的气溶胶元素含量远高于扎当冰川区, 这是 因为青藏高原的大气气溶胶空间分布为“北高南 低”[4]. 瓦里关站和五道梁位于青藏高原北部, 距中 国北部沙尘源区很近, 因而大气粉尘含量较高. 与之 类似, 尽管珠穆朗玛峰南坡采样点位于青藏高原南 部，但由于海拔也较低 $(5100 \mathrm{~m})$, 且地表裸露较多, 局地气溶胶的输入量较大, 而且该样品是在季风前 大气气溶胶含量较高时采集的，所以垭口冰川区大 部分元素含量也远低于该地区 ${ }^{[18]}$.

以上对比说明，扎当垭口冰川区的大气非常洁

表 2 扎当垭口冰川区气溶胶元素含量与其他地区对比(单位: $\mathrm{ng} / \mathrm{m}^{3}$ )

\begin{tabular}{|c|c|c|c|c|c|c|c|c|c|c|}
\hline \multirow{3}{*}{ 元素 } & \multicolumn{8}{|c|}{ 青藏高原 } & \multirow{3}{*}{ 南极洲 e) } & \multirow{3}{*}{ 北京 f) } \\
\hline & \multicolumn{4}{|c|}{ 扎当垭口 } & \multicolumn{4}{|c|}{ 青藏高原其他地点 } & & \\
\hline & 最小值 & 最大值 & 平均值 & SD & 纳木错站 ${ }^{\text {a) }}$ & 瓦里关站 b) & 珠穆朗玛峰南坡 ${ }^{c)}$ & 五道梁 ${ }^{d)}$ & & \\
\hline $\mathrm{Li}$ & 0.007 & 0.191 & 0.053 & 0.061 & & & & & & \\
\hline $\mathrm{Be}$ & 0.000 & 0.009 & 0.002 & 0.003 & & & & & & \\
\hline B & 0.000 & 2.138 & 0.541 & 0.814 & & & & & & \\
\hline $\mathrm{Na}$ & 0.135 & 43.697 & 12.023 & 13.972 & & $541 \sim 1150$ & & 11713.72 & & 1600 \\
\hline $\mathrm{Mg}$ & 2.049 & 64.257 & 17.793 & 20.956 & 12 & $1430 \sim 3230$ & 490 & 4118.56 & & 2040 \\
\hline $\mathrm{Al}$ & 4.910 & 188.125 & 57.071 & 60.308 & 131 & $2110 \sim 3410$ & & 21390.48 & 1.875 & 5330 \\
\hline K & 2.479 & 96.212 & 26.997 & 30.690 & 82 & $1190 \sim 2200$ & 392 & & & \\
\hline $\mathrm{Ca}$ & 3.978 & 144.963 & 51.139 & 59.830 & 251 & $2010 \sim 4280$ & 483 & & & 9050 \\
\hline $\mathrm{Sc}$ & 0.000 & 0.035 & 0.010 & 0.011 & & $0.52 \sim 1.4$ & 0.16 & 3.83 & & \\
\hline $\mathrm{Ti}$ & 0.120 & 12.440 & 3.675 & 4.059 & 10 & $106 \sim 220$ & 73 & 716.13 & & 330 \\
\hline $\mathrm{V}$ & 0.000 & 0.661 & 0.281 & 0.212 & 0.06 & $3.02 \sim 5.88$ & 1.3 & & 0.036 & \\
\hline $\mathrm{Fe}$ & 0.000 & 69.971 & 21.167 & 23.243 & 94 & $1720 \sim 3910$ & 500 & 10453.67 & & 3730 \\
\hline $\mathrm{Mn}$ & 0.000 & 2.500 & 0.839 & 0.740 & 3.7 & $27.5 \sim 52.9$ & 11.4 & 192.5 & & 110 \\
\hline $\mathrm{Zn}$ & 0.096 & 8.566 & 2.446 & 2.702 & 1.8 & $9.5 \sim 26.3$ & 11.2 & & 0.13 & 330 \\
\hline $\mathrm{Ga}$ & 0.000 & 0.060 & 0.016 & 0.020 & & & & 6.55 & 0.0005 & \\
\hline As & 0.000 & 0.370 & 0.135 & 0.130 & 0.04 & $0.70 \sim 3.37$ & 0.14 & & & 20 \\
\hline $\mathrm{Rb}$ & 0.019 & 0.466 & 0.141 & 0.147 & & $6.2 \sim 14.9$ & 1.9 & 40.96 & 0.0062 & \\
\hline $\mathrm{Sr}$ & 0.022 & 1.279 & 0.317 & 0.420 & & & & 94.36 & 0.684 & 20 \\
\hline $\mathrm{Y}$ & 0.002 & 0.058 & 0.018 & 0.019 & & & & 4.33 & & \\
\hline $\mathrm{Cd}$ & 0.000 & 0.043 & 0.009 & 0.014 & & & 0.04 & & 0.0013 & 2.43 \\
\hline Cs & 0.004 & 0.064 & 0.021 & 0.020 & & & 0.22 & & 0.0002 & \\
\hline $\mathrm{Ba}$ & 0.000 & 1.390 & 0.466 & 0.549 & & & & & 0.0103 & \\
\hline $\mathrm{Tl}$ & 0.001 & 0.009 & 0.003 & 0.003 & & & & & 0.0002 & \\
\hline $\mathrm{Pb}$ & 0.081 & 0.762 & 0.294 & 0.217 & & & 4.4 & & 0.041 & 110 \\
\hline $\mathrm{Bi}$ & 0.000 & 0.020 & 0.006 & 0.006 & & & & & 0.0003 & \\
\hline Th & 0.002 & 0.039 & 0.012 & 0.012 & & & 0.21 & 2.72 & & \\
\hline U & 0.001 & 0.016 & 0.004 & 0.005 & & & 0.026 & & 0.0003 & \\
\hline
\end{tabular}

a) 2005 年 7 10 月采集的气溶胶，海拔 $4718 \mathrm{~m}^{[15]}$; b) 1992 1995 年采集的气溶胶，海拔 $3814 \mathrm{~m}^{[11]}$; c) 2002 年 $3 \sim 5$ 月采集的气溶胶，海拔

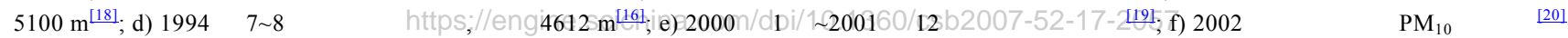


净, 代表了青藏高原对流层中上部的大气状况. 但冰 川区几乎所有元素的含量都高于南极洲, 这与南极 大陆几乎被冰雪覆盖且远离人类聚居区有关. 由于 北京的高沙尘和高污染, 冰川区几乎所有元素的含 量远低于北京几个数量级 ${ }^{[20]}$.

\section{2 气溶胶来源探讨}

（i ）富集因子。富集因子(enrichment factors, 简称EFs) 是Zoller等人 ${ }^{[22]}$ 在研究南极上空大气颗粒物 中元素的来源时首次提出的. 这一方法在提出后应 用领域迅速扩大, 尤其在环境地球化学重金属的污 染评价中得到广泛应用。

研究中一般选择 $\mathrm{Al}$ 作为参考元素, 地壳元素的 平均含量通常采用 Taylor和McLennan ${ }^{[23]}$ 提出的上地 壳(UCC)元素数据. 富集因子可表示为

$$
E F_{X}=\frac{\left(C_{X} / C_{R}\right)_{\text {气溶胶 }}}{\left(C_{X} / C_{R}\right)_{\text {地壳 }}},
$$

其中 $C_{X}$ 代表待检验元素, $C_{R}$ 代表参考元素, $E F_{X}$ 指待评 价元素的富集因子值. 本文以A1作为参考元素, 把富集 因子高于 10 的元素视为受到了人类活动的污染 ${ }^{[15]}$.

图 3 给出了垭口冰川区测定元素相对上地壳元 素Al的富集因子. 从图 3 上可以看出地壳元素如 $\mathrm{Mg}$,
$\mathrm{Ca}, \mathrm{Ga}, \mathrm{Rb}$ 等的富集因子都在 1 左右, 表明这些元素 主要为自然源粉尘, 并且粉尘在长距离传输过程中 充分混合而与上地壳元素的组成十分接近. 而元素B, $\mathrm{Zn}, \mathrm{As}, \mathrm{Cd}, \mathrm{Pb}, \mathrm{Bi}$ 的富集因子都高于 10 , 其中 $\mathrm{As}$ 和 $\mathrm{Cd}$ 的富集因子超过 100 , 说明这两种元素受到了人类活 动的强烈影响. 这些元素除了少量自然源外有着复 杂的人为来源, 如 $\mathrm{Pb}$ 除来自含铅汽油的燃烧外, 还有 诸如电池生产、废弃物燃烧和冶炼工业等的排放 ${ }^{[24]}$; $\mathrm{Zn一}$ 一般来自化石燃料的燃烧、金属冶炼以及垃圾焚烧 等活动 ${ }^{[25,26] ; C d}$ 则广泛用于合金、电镀、染料等行业 [27]. 青藏高原工业活动极少, 而这些重金属污染在南 亚的大城市普遍存在. 从气溶胶粒度谱看, 印度港市 Visakhapatnam的大气细粒气溶胶中污染元素的含量 远大于粗粒级的, 而且近年来细粒气溶胶含量逐年

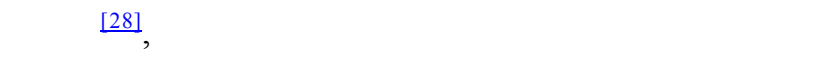
气溶胶重金属元素的含量远低于非季风期间, 说明 季风期间的污染物更易扩散到其他地方, 同时该市 大气气溶胶中 $\mathrm{Cd}$ 和 $\mathrm{Pb}$ 强烈富集, $\mathrm{EF}$ 最高值都超过 $50000^{[24]}$, 而孟加拉国首都达卡大气气溶胶中的 As, $\mathrm{Zn}$ 和 $\mathrm{Pb}$ 也都高度富集, 达到 1000 左右 ${ }^{[29]}$. 由于 $\mathrm{Cd}$, $\mathrm{Zn}, \mathrm{Pb}$ 在冰川区有较高的EF值, 可以推测冰川区气溶 胶中的这些重金属主要来自南亚污染严重

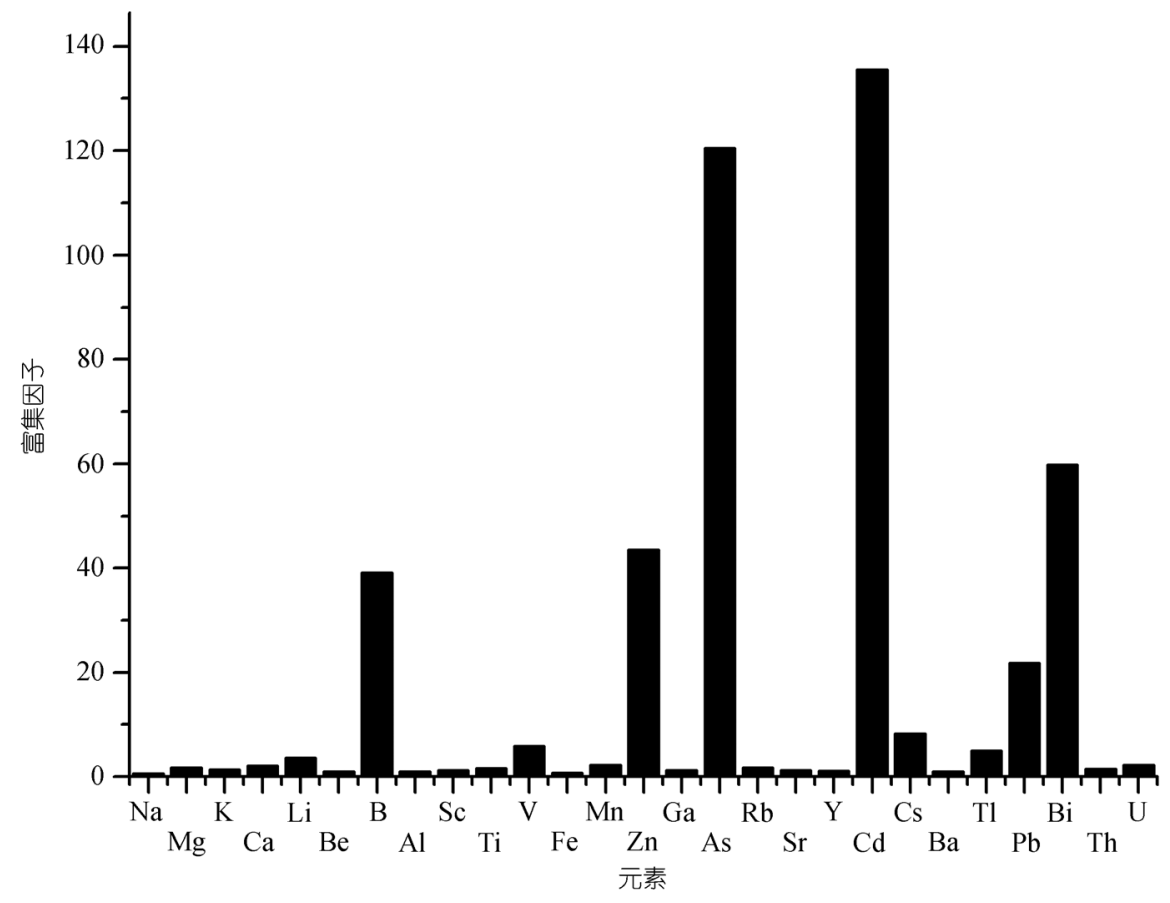

图 3 元素的富集因子 
的大城市. 不过由于青藏高原的土壤中As含量较高 [30], 所以部分As 可能来自青藏高原自然源粉尘的贡 献.

青藏高原冰雪和大气气溶胶中已检测到了人类 活动的影响. Xiao等人 ${ }^{[21,4]}$ 在对青藏高原从南到北不 同地区雪坑的离子和元素含量的研究中发现, 在空 间上青藏高原的粉尘气溶胶含量“南低北高”，而重 金属含量却是“南高北低”，从而在一个侧面证明雪 冰中的重金属以人为源占主导且主要来自南亚. 在 青藏高原北部瓦里关站 ${ }^{[11]}$ 和五道梁 ${ }^{[13]}$ 气溶胶的研究 中都没有检测到从南亚远距离传输的大气污染物, 可能原因是印度季风只能延伸到唐古拉山地区而不 能到达这些地点 ${ }^{[31]}$. 位于青藏高原南部的纳木错站大 气气溶胶中地壳元素含量比瓦里关站和五道梁的值低 很多 ${ }^{[15]}$, 而且由于其研究时段集中在季风期间, 因而 比较容易捕捉到来自南亚的污染物. 本文位于高海拔
冰川区的研究地点与纳木错站相比, 受局地粉尘的影 响更小，因而对来自南亚的污染物更敏感，其中 $\mathrm{Zn}$ 和 As的富集因子比纳木错站高数倍也是佐证.

(ii) 气团轨迹分析. 为了探讨垭口冰川区气溶 胶的可能传输路径, 利用NOAA Air Resources Laboratory提供的HYSPLIT 气团轨迹模型结合FNL气象数据 库 (http://www.arl.noaa.gov/ready/open/hysplit4.html), 计算了垭口采样期间的气团轨迹 $(7 \mathrm{~d}$ 回溯, 气团高度 分为地面以上 $100,500,1000 \mathrm{~m} 3$ 层), 该轨迹包括气 团运移路径和气团的高度变化, 计算出的气团轨迹 误差为 $20 \%$ 左右, 因此轨迹图表示的是气团移动的 大体路径 [32]. 大部分气团轨迹图显示采样期间气团 穿越了印度次大陆和孟加拉湾, 本文只给出其中一 次典型的轨迹图(图 4). 从图 4 可出, 气团起源于孟加 拉湾, 经过印度东北部和孟加拉国向北翻越喜马拉 雅山到达采样地点.

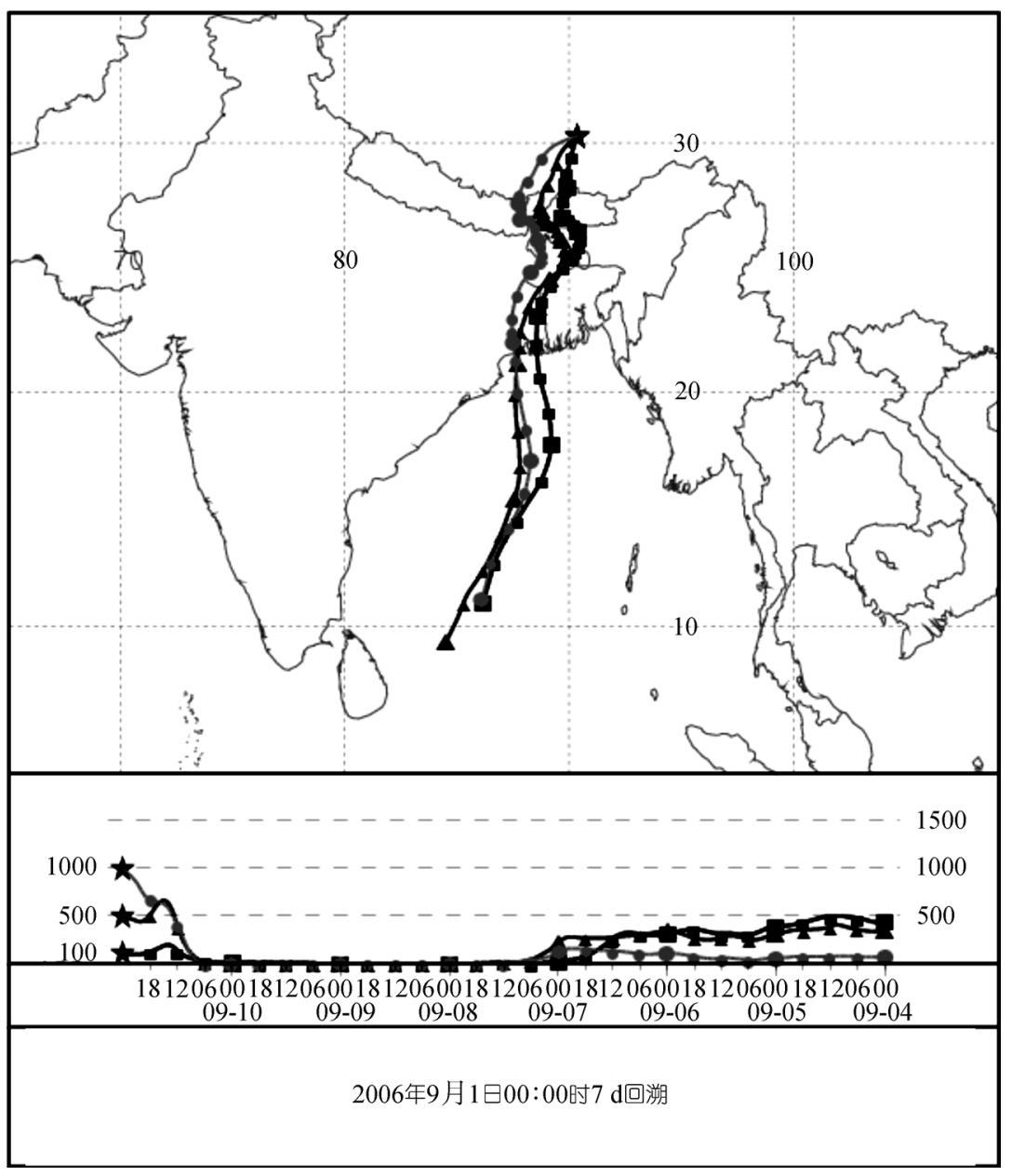

图 4 ci采样期间一次典型的气团轨迹图 
在过去 20 年中随着南亚工业和经济的快速发展, 该地区气溶胶和大气污染物的排放量也急剧增加. 印度、孟加拉国的大气污染十分严重 ${ }^{[24,33,34]} .2002$ 年 在印度次大陆观察到的由大气污染物形成的褐色云 团使这一地区的大气污染更引人注目 ${ }^{[35]}$. 这些污染 物不仅对局地, 而且可能对其周边地区及青藏高原 的农业、气候产生影响. 对印度次大陆大气污染物传 输过程的研究进一步表明, 西南夏季风可以通过强 烈的对流作用把该地区边界层的污染物传输到对流 层上部, 而在印度东北部进入对流层上部的污染物 受到青藏高原夏季产生的强大反气旋的吸引能直接 进入青藏高原 [36]. 除了污染物的高空传输机制外, 喜马拉雅山南坡的大气污染物也能通过山谷风的作 用翻越喜马拉雅山, 传输到青藏高原 ${ }^{[37]}$. 青藏高原 降水中氧稳定同位素比率的研究表明印度季风在青 藏高原的影响范围可以延伸到唐古拉山一带 [31], 因 而南亚的大气污染物随着西南夏季风完全可以传输 到念青唐古拉峰地区.

\section{3 结论}

本文测定了夏季风期间青藏高原南部念青唐古 拉峰冰川区大气气溶胶 27 种元素的含量. 结果表明, 冰川区大部分元素, 尤其是地壳元素的含量比该地 区同期低海拔的元素含量低, 也比高原面上其他地 区的值低很多. 因此, 冰川区夏季大气非常洁净, 代 表了青藏高原对流层中上部大气气溶胶元素含量的 背景值, 为青藏高原冰川区气溶胶元素特征提供了 重要基础数据.

在夏季风期间直接采集青藏高原冰川区大气气 溶胶并揭示来自南亚污染物的研究, 不但支持了通 过青藏高原冰雪和低海拔大气气溶胶研究发现的重 金属污染，还检测到了更多的来自人类污染物的元 素. 冰川区气溶胶元素富集因子表明 $\mathrm{B}, \mathrm{Zn}, \mathrm{As}, \mathrm{Cd}$, $\mathrm{Pb}, \mathrm{Bi}$ 存在一定程度的富集, 而且富集程度比该地区 低海拔同期高, 说明冰川区能更为灵敏的反映大气 重金属污染. 印度和孟加拉国较为严重的大气重金 属污染以及夏季风期间气团主要来自南亚佐证了念 青唐古拉峰地区的大气环境受到南亚人类污染物的 影响.

致谢 梁茂辉和次仁多杰为样品的野外采集付出了辛勤的 劳动，高少鹏为样品的室内分析作了细致的工作，黄杰、游 庆龙、张拥军等对本文的完成也提供很大帮助, 在此表示
感谢.

\section{参考 文献}

1 Bishop J K B, Davis R E, Sherman J T. Robotic observations of dust storm enhancement of carbon biomass in the North Pacific. Science, 2002, 298(5594): 817-821[DOI]

2 Seinfeld J H, Carmichael G R, Arimoto R, et al. ACE-ASIA: Regional climatic and atmospheric chemical effects of Asian dust and pollution. Bull Am Meteorol Soc, 2004, 85(3): 367-380[DOI]

3 Nishikawa M, Kanamori S, Kanamori N, et al. Kosa aerosol as eolian carrier of anthropogenic material. Sci Total Environ, 1991, 107: 13-27[DOI]

4 效存德, 秦大河, 姚檀栋, 等. 南、北极和青藏高原现代降水中 $\mathrm{Pb}, \mathrm{Cd}$ 反映的全球大气污梁. 科学通报, 1999, 44(23)：25582563

5 Lammel G, Rohrl A, Schreiber H. Atmospheric lead and bromine in Germany: Post-abatement levels, variabilities and trends. Environ Sci Pollut Res, 2002, 9: 397-404

6 Maring H B, Duce R A. The impact of atmospheric aerosols on trace metal chemistry in open ocean surface seawater. 3. Lead. J Geophys Res, 1990, 95(C4): 5341—5347

7 Xiao C D, Qin D H, Yao T D, et al. Spread of lead pollution over remote regions and upper troposphere: Glaciochemical evidence from polar regions and Tibetan Plateau. Bull Environ Contam Toxicol, 2001, 66(6): 691-698[DOI]

8 Kang S C, Qin D H, Mayewski P A, et al. Evidence of the Kuwaiti oil fires in the Dasuopu Glacier ice core, central Himalaya. J Glaciol, 2001, 47(158): 519—520

9 Kang S C, Mayewski P A, Qin D H, et al. Twentieth century increase of atmospheric ammonia recorded in Mt. Everest ice core. J Geophys Res, 2002, 107(D21): 4595

10 李月芳, 姚檀栋, 王宁练, 等. 青藏高原古里雅冰芯中痕量元素镉 记录的大气污染, 1900 1991. 环境化学, 2000, 19(2): 176-180

11 温玉璞, 徐晓斌, 汤洁, 等. 瓦里关山大气气溶胶元素的富集特 征和源区. 应用气象学报, 2001, 12(4): 401-408

12 杨龙元, 王明星, 吕国涛, 等. 青藏高原北部陆源气溶胶背景特 征的观测和研究. 高原气象, 1994, 13(2): 135-143

13 柳海燕, 张小电, 沈志宝. 青藏高原五道梁低层大气气溶胶来源的 初步分析 I. 因子分析结果. 高原气象, 1997, 16(4): 337-344

14 张小曳, 沈志宝, 张光宇, 等. 青藏高原远源西风粉尘与黄土堆 积. 中国科学 D 辑: 地球科学, 1996, 26(2): 147-153

15 Cong Z Y, Kang S C, Liu X D, et al. Elemental composition of aerosol in the Nam Co region, Tibetan Plateau, during summer monsoon season. Atmos Environ, 2007, 41: 1180-1187[DOI]

16 柳海燕, 张小电, 沈志宝. 五道梁大气气溶胶的化学组成和浓度 及其季节变化. 高原气象, 1997, 16(2):122-129

17 Kang S C, Mayewski P A, Qin D H, et al. Glaciochemical records from a Mt. Everest ice core: Relationship to atmospheric 3 circulation Oover 2 Asia. Atmos Environ, 2002, 36(21): $3351-$ 


\section{$3361[\mathrm{DOI}$}

18 Giaveri G, Bergamaschi L, Rizzio E, et al. INAA at the top of the world: Elemental characterization and analysis of airborne particulate matter collected in the Himalayas at $5100 \mathrm{~m}$ high. J Radioanal Nucl Chem, 2005, 263(3): 725-732[DOI]

19 Mishra V K, Kim K H, Hong S, et al. Aerosol composition and its sources at the King Sejong Station, Antarctic peninsula. Atmos Environ, 2004, 38(24): 4069-4084[DOI]

20 Sun Y L, Zhuang G S, Wang Y, et al. The air-borne particulate pollution in Beijing-concentration, composition, distribution and sources. Atmos Environ, 2004, 38: 5991-6004[DOI]

21 Xiao C D, Kang S C, Qin D H, et al. Transport of atmospheric impurities over the Qinghai-Xizang (Tibetan) Plateau as shown by snow chemistry. J Asian Earth Sci, 2002, 20: 231-239[DOI]

ric concentration and sources of trace metals at the South Pole. Science, 1974 183(4121): 198-200

23 Taylor S R, McLennan S M. The geochemical evolution of the continental crust. Rev Geophys, 1995, 33(2): 241-265[DOI]

24 Khillare P S, Balachandran S, Meena B R. Spatial and temporal variation of heavy metals in atmospheric aerosol of Delhi. Environ Monit Assess, 2004, 90: 1-21[DOI] atmospheric aerosol at urban and suburban residential areas in Thailand by positive matrix factorization. Atmos Environ, 2000, 34: $3319-3329$ [DOI]

26 Rogge W F, Hildemann L M, Mazurek M A, et al. Sources of fine organic aerosol. 3. Road dust, tire debris, and organometallic brake lining dust: Roads as sources and sinks. Environ Sci Technol, 1993 27(9): 1892-1904[DOI]

27 Pacyna J M. Atmospheric trace elements from natural and anthropogenic sources. In: Nriagu J O, Davidson C I, eds. Toxic
Elements in the Atmosphere. New York: John Wiley Sons, 1986. $33-52$

28 Niranjan K, Thulasiraman S, Satyanarayana G V, et al. Temporal Characteristics of Aerosol Optical Depths and Size Distribution at Visakhapatnam, India. Aerosol Sci Technol, 2000, 32(4): 284292[DOI]

29 Begum B A, Biswas S K, Kim E, et al. Investigation of sources of atmospheric aerosol at a hot spot area in Dhaka, Bangladesh. J Air Waste Manage Assoc, 2005, 55(2): 227-240

30 成延鏊, 田均良. 西藏土壤元素背景值及其分布特征. 北京: 科 学出版社, 1993. 12

31 Tian L, Masson-Delmotte V, Stievenard M, et al. Tibetan Plateau summer monsoon northward extent revealed by measurements of water stable isotopes. J Geophys Res-Atmos, 2001, 106(D22): 28081-28088[DOI]

32 Stohl A. Computation, accuracy and applications of trajectories-A review and bibliography. Atmos Environ, 1998, 32: 947-966[DOI]

33 Monkkonen P, Uma R, Srinivasan D, et al. Relationship and variations of aerosol number and $\mathrm{PM}_{10}$ mass concentrations in a highly polluted urban environment-New Delhi, India. Atmos Environ, 2004, 38: 425-433[DOI]

34 Begum B A, Kim E, Biswas S K, et al. Investigation of sources of atmospheric aerosol at urban and semi-urban areas in Bangladesh. Atmos Environ, 2004, 38: 3025-3038[DOI]

35 UNEP and C4. The Asian Brown Cloud: Climate and Other Environmental Impacts. Nairobi: UNEP, 2002. 63

36 Li Q, Jacob D J, Logan J A, et al. A tropospheric ozone maximum over the Middle East. Geophys Res Lett, 2001, 28(17): 3235$3238[\mathrm{DOI}]$

37 Hindman E E, Upadhyay B P. Air pollution transport in the Himalayas of Nepal and Tibet during the 1995-1996 dry season. Atmos Environ, 2002, 36(4): 727-739[DOI] 